\section{Satisfaction with maternal care in migrants and natives: a population-based study from Portugal Anna Muralova}

A Muralova', C Teixeira ${ }^{2}$, H Barros ${ }^{1,3}$

${ }^{1}$ EPIUnit - Instituto de Saúde Pública, Universidade do Porto, Porto, Portugal ${ }^{2}$ Instituto Politécnico de Bragança, Bragança, Portugal

${ }^{3}$ Departamento de Ciências de Saúde Pública e Forenses e Educação Médica, Faculdade de Medicina da Universidade do Porto, Porto, Portugal Contact: ana.muralova@gmail.com

Background:

Women's satisfaction is an indicator of maternal healthcare quality. As migrant population contributed for $8.8 \%$ of births in Portugal in 2016, maternal care providers should evaluate the effect of multicultural diversity in women's satisfaction. The aim of this paper is to assess the degree of maternal satisfaction with care during labour and delivery by migrant groups in Portugal.

\section{Methods:}

This is a part of the baMBINO project, an ongoing populationbased study enrolling native and foreign-born women recruited in 32 Portuguese public hospitals during admission for delivery. For this analysis, foreign-born women $(n=1385)$ were classified into long-term (LT, $>8$ years) and recent (RM) migrants from Portuguese Speaking African Countries (PSAC), Brazil (B) and Non-Portuguese Speaking Countries (NPSC). Such groups were compared with native women $(\mathrm{n}=1167)$ for the prevalence of satisfaction with healthcare received, time spent by the professionals in providing explanations, how professionals were respectful, helpful and encouraging. Multivariate logistic regression models were used.

\section{Results:}

There was variation between groups for the prevalence of satisfaction with healthcare received $(\mathrm{p}<0.001)$ from $90.8 \%$ (B-RM) to $98.1 \%$ (PSAC-RM); time spent by professionals to provide explanations $(\mathrm{p}<0.004)$ from $88,3 \%$ (NPSC-RM) to 93,2\% (PSAC-RM); how professionals were helpful ( $p=0.035)$ from $94,3 \%(B-R M)$ to $98,6 \%$ (B-LTM), respectful $(\mathrm{p}=0.038)$ from $93.6 \%(\mathrm{~B}-\mathrm{RM})$ to $98.4 \%(\mathrm{NPSC}-\mathrm{LT})$ and encouraging $(\mathrm{p}=0.002)$ from $88.7 \%(\mathrm{~B}-\mathrm{RM})$ to $96.5 \%$ (B$\mathrm{LT})$. Differences remained after adjusting for maternal age, educational level, mode of delivery and complications.

\section{Conclusions:}

Although the prevalence of satisfied women is high, there is heterogeneity in the satisfaction with some aspects of maternal care between groups of migrant women.

Key messages:

- Professionals should be aware about the effect of cultural background in women's satisfaction with care.

- It is important to consider significance of determinants of satisfaction to improve care for migrants. 